\title{
ENSINO SUPERIOR: TRAJETÓRIAS E SABERES DOCENTES
}

\author{
Ana Paula Pereira Arantes ${ }^{(1)}$, Raimunda Abou Gebran ${ }^{(2)}$ \\ ${ }^{(1)}$ Diretora Acadêmica e Docente do curso de Pedagogia da Faculdade Aldete Maria Alves - FAMA., ${ }^{(2)}$ Docente do Programa de \\ Mestrado em Educação da Universidade do Oeste Paulista - UNOESTE. E-mail: annaapaulaa@hotmail.com
}

\section{RESUMO}

Esta pesquisa teve como objetivo compreender a trajetória e os saberes dos professores atuantes no curso de Pedagogia em uma instituição privada (faculdade), analisando a sua formação, suas concepções sobre educação, influências sofridas e experiências vividas, a fim de traçar um perfil do professor atuante no curso de Pedagogia. A pesquisa se desenvolveu na abordagem qualitativa. Os procedimentos de pesquisa que viabilizaram a consecução do objetivo pretendido foram: aplicação de questionários, pesquisa documental e entrevistas semiestruturadas. Participaram da pesquisa professores do Curso de Pedagogia de uma instituição privada do interior de Minas Gerais. Os docentes participantes da pesquisa (06) foram selecionados por núcleo de formação no qual está estruturada a matriz curricular do curso: estudos básicos, aprofundamento e estudos integradores. Selecionamos, por sorteio, dois docentes de cada núcleo, que possuíam mais de um ano de atuação docente no curso de Pedagogia e concordaram em participar de forma anônima da pesquisa. A análise dos dados coletados revelou aspectos significativos no tocante à sua formação e atuação, a saber: ausência de formação e preparação didática para a docência no ensino superior, privilégio do ensino e pouco envolvimento dos docentes com atividades de pesquisa e a extensão, predominância de aulas expositivas e falta organização e desenvolvimento de projetos coletivos e interdisciplinares. O ensinar envolve um arcabouço de saberes que influenciam na própria ação docente. Isso remete à compreensão de que o trabalho docente se concretiza por meio da práxis, na relação teoria e prática referendada na reflexividade (ação-reflexão-ação).

Palavras-chave: Ensino Superior. Curso de Pedagogia. Trajetórias e saberes docentes.

\section{HIGHER EDUCATION: TRAJECTORIES AND KNOWLEDGE OF THE TEACHERS}

\begin{abstract}
This research aimed at understand the trajectory and knowledge of active teachers in the Pedagogy course at a private institution (college), analyzing their formation, their concepts on education, experiences and suffered influences in order to outline a profile of teachers working in Pedagogy course. The research was developed in the qualitative approach, using the procedure as a case study. The research procedures that enabled the achievement of intended goals were questionnaires, documentary research and semi-structured interviews. Teachers participated in the study of the Pedagogy Course from a private institution in Minas Gerais. The faculty participants were selected by a core training which is structured the curriculum of the course: basic studies and further studies integrators. Selected by lot, two teachers from each core, which had more than one year of performance in the teaching pedagogy course and which have agreed to participate anonymously in the survey. The analysis of collected data revealed significant aspects with regard their formation and expertise, namely: absence of didactic training and preparation for teaching in higher education, the privilege of teaching and low involvement of teachers with research and extension activities, the predominance of expositive class and lack organization and development of projects and interdisciplinary. Finally we understand that teaching involves a framework of knowledge that presented itself in the classroom. This refers to the understanding that teaching is concretized through praxis, theory and practice in relation referenced on reflexivity (action-reflection-action).
\end{abstract}

Keywords: Higher education. Pedagogy Course. Trajectories and teacher knowledge. 


\section{INTRODUÇÃO E OBJETIVO}

A formação de professores é temática presente em vários Seminários, Encontros, Ciclos de Palestras e outros eventos do meio acadêmico. Porém, de acordo com Vasconcelos (2000) a ênfase destas discussões não privilegia o ensino superior.

Considerando os dados do Censo 2008, temos no Brasil um número inferior de matrículas no ensino superior presencial (5.080.056), comparando com 0 ensino fundamental (31.694.497) e médio (8.272.159). (BRASIL. Ministério da Educação, 2009). Entretanto, o número de instituições de ensino superior no Brasil vem crescendo de forma significativa; em 20 anos houve um aumento de 158,55\%, uma vez que em 1988 existiam 871 (BRASIL, MEC, 2000, p.13) e em 2008 eram 2.252 instituições. (BRASIL, MEC, 2009).

Segundo Gil (1997) à medida que o maior número de pessoas chega ao ensino superior, o controle sobre a qualidade do ensino e a capacitação dos professores decai. Tanto é que se torna muito frequente que os alunos do ensino superior, ao fazerem a apreciação de seus professores, ressaltam a sua competência técnica e criticam a sua didática.

Isso pode ser atribuído ao fato de que muitos professores são bons profissionais na sua área de formação (direito, administração, contabilidade, etc.), reconhecidos pelo desempenho no mercado de trabalho e logo são convidados a ministrar aulas.

O exercício docente no ensino superior exige competências especificas que não se restringem a ter um diploma de bacharel, ou mesmo de mestre ou doutor, ou, ainda, apenas o exercício de uma profissão. Exige isso tudo, além de outras competências próprias. (MASETTO, 1998, p.11)
Portanto, para o exercício docente no ensino superior, não basta que o professor tenha apenas o domínio do conteúdo, ele deve contribuir para uma situação de aprendizagem.

Outra variável que intensifica a relevância desta análise diz respeito aos poucos critérios legais que definem a formação pedagógica exigida ao docente do ensino superior.

Vasconcelos (2000, p. 17) afirma que na Lei 9394/96 "não há nenhuma alusão à formação didático-pedagógica como pré-requisito para a formação, ingresso e promoção na carreira docente do magistério superior".

Como critério para o exercício da docência no ensino superior a LDB determina em seu artigo 66 que "a preparação para o exercício do magistério superior far-se-á em nível de pósgraduação, prioritariamente em programas de mestrado e doutorado".

Desta forma entende-se que a formação do professor do ensino superior está voltada, prioritariamente, para a pesquisa, conforme os padrões de qualidade determinados pelo MEC/ CAPES para a pós-graduação stricto sensu.

Não se trata de negar a importância da pesquisa para o aprofundamento do seu campo científico, mas sim de situá-la em sintonia e interpenetração com outras dimensões, tão necessárias e complexas para construção da identidade do ser professor. Dimensões estas que podem ser definidas enquanto saberes docentes.

Pode-se definir o saber docente como um saber plural, formado pelo amálgama, mais ou menos coerente, de saberes oriundos da formação profissional e de saberes disciplinares, curriculares e experienciais. (TARDIF, 2002, p. 36)

Portanto, cada professor possui uma bagagem de conhecimentos advindos de um processo individual de construção, de formação e 
de desenvolvimento profissional, que influencia o seu fazer pedagógico e manifesta-se em significados distintos em sua prática pedagógica. Conhecer quais são estas influências e manifestações compreendendo a trajetória e os saberes dos professores atuantes no Curso de Pedagogia em uma instituição privada, analisando a sua formação, suas concepções, influências sofridas e experiências vividas, a fim de traçar um perfil do professor atuante no curso de Pedagogia constitui o objetivo do presente trabalho.

\section{METODOLOGIA}

Esta pesquisa se desenvolveu na
abordagem qualitativa, utilizando como
procedimento o estudo de caso. A delimitação do
universo de pesquisa ocorreu por amostragem do
tipo probabilística. Os instrumentos de pesquisa
que viabilizaram a consecução dos objetivos
pretendidos foram pesquisa bibliográfica,
documental, questionário e entrevista
semiestruturada.

Por ser uma pesquisa que envolve seres humanos, a mesma foi cadastrada, avaliada e aprovada antes da sua realização pelo Comitê de Ética e Pesquisa da UNOESTE sob o número 386.

Os docentes participantes da pesquisa foram selecionados por núcleo de formação no qual está estruturada a matriz curricular do curso de Pedagogia em estudo, ou seja: núcleo de estudos básicos, núcleo de aprofundamento e núcleo de estudos integradores.

Foram selecionados, por sorteio, dois docentes de cada núcleo, que possuíam mais de um ano de atuação docente no curso de Pedagogia e concordaram em participar de forma anônima da pesquisa. Participaram da pesquisa seis professores, que foram identificados como: P1 e P6 - professores atuante nas disciplinas do núcleo de estudos básicos, P3 e P4 - professores atuante nas disciplinas do núcleo de aprofundamento, P5 e P2 - professores atuante nas disciplinas do núcleo de estudos integradores.

O último passo da pesquisa caracterizouse pela análise e interpretação dos dados obtidos tendo como referência a análise de conteúdos e utilizando como referencia a técnica de mapeamento.

Essa análise norteou-se de acordo com os seguintes tópicos: o perfil e a trajetória formativa dos professores atuantes no curso de Pedagogia, o processo de inserção e atuação docente no ensino superior e os saberes do professor atuante no curso de pedagogia.

\section{RESULTADOS E DISCUSSÃO PERFIL E A TRAJETÓRIA FORMATIVA DOS PROFESSORES ATUANTES NO CURSO DE PEDAGOGIA}

Os professores participantes da pesquisa são, em sua maioria, do sexo feminino (5 docentes), com idade entre 25 e 64 anos.

No que se refere à trajetória formativa destes professores todos possuem curso de licenciatura e de pós-graduação lato sensu, porém, nenhum possui pós-graduação stricto sensu, não cumprindo portanto os critérios legais expostos no artigo 66 da LDB 9394/96 referente à docência no ensino superior.

Referente ao início da carreira docente foi identificado nas falas dos professores momentos da descoberta concomitante com o choque com a realidade, de arrependimento e a antecipada entrada no mercado de trabalho em detrimento do tempo de formação.

Esta entrada antecipada no mercado de trabalho criou nos professores uma falsa ideia de suficiência da vocação para o exercício do magistério.

Então eu conseguia, mesmo sendo aluna da $7^{\underline{a}}$ série e sem nenhuma preparação para a docência, alfabetizar com sucesso aqueles alunos, 
sempre tive o dom para ser professora. (P4)

Grillo e Mattei (2005, p. 104) recusam a ideia de que se aprende a ensinar ensinando, sendo assim suficiente apenas a vocação, o que atribuiria à docência um caráter amador, não sendo necessária uma preparação.

A prática que efetivamente sustenta o eixo empírico não é qualquer prática. É sustentada por um corpo de conhecimentos teóricos sempre em construção, que a alimentam, que a explicam e que estabelecem a relação dialética teoria/prática. A prática, ao ser iluminada pela teoria, torna a teoria mais clara, compreensível e revigorada.

Shulman (2005) acredita que para ser professor o indivíduo deve dominar uma base de conhecimentos para o ensino (knowledge base), que estruture a formação de professores e influencie diretamente na prática dos mesmos. Esta base de conhecimentos compreende: 0 conhecimento do conteúdo específico que o professor leciona (content knowledge), o conhecimento pedagógico geral (pedagogical knowledge) o qual inclui conhecimento de teorias e princípios relacionados ao processo ensinoaprendizagem e o conhecimento pedagógico do conteúdo no ensino (content knowledge in teaching), que é construído constantemente pelo professor ao ensinar a matéria e que é enriquecido e melhorado quando se relaciona com outros conhecimentos pertencentes à base.

Verificamos que a falta desta base de conhecimento nos professores que iniciaram a carreira antes de concluir, ou mesmo iniciar, a sua formação para docência, era suprida por orientação de colegas de trabalho.

[...] a gente tinha um acompanhamento, a inspetora regional, seccional, que se chamava na época, era aqui de Iturama então nos ajudou muito a nós "alunas professoras. (P4)
Referente às formas de capacitação profissional dos docentes sujeitos da pesquisa, estas compreendem principalmente cursos ministrados pela Secretaria de Estado da Educação de Minas Gerais, cursos de pósgraduação e leituras individuais. Estas formas de capacitação referem-se à educação básica. Nenhum dos sujeitos desta pesquisa citou alguma capacitação específica para a docência no ensino superior.

Me capacito através dos cursos em que o próprio governo estou instituição a qual estou inserida oferece. Também busco cursos de especialização. (P1)

Busco me capacitar através das capacitações que tenho como funcionário público municipal do Estado de Minas, então há capacitações feitas no Estado, pelo menos 1 ou 2 por ano tem, então eu procuro ir nestas capacitações porque voltadas para as atividades do Estado [...].(P5)

A formação permanente docente através da reflexão prático-teórica sobre a prática não foi considerada pela maioria dos professores (5), sendo citada apenas por um dos entrevistados.

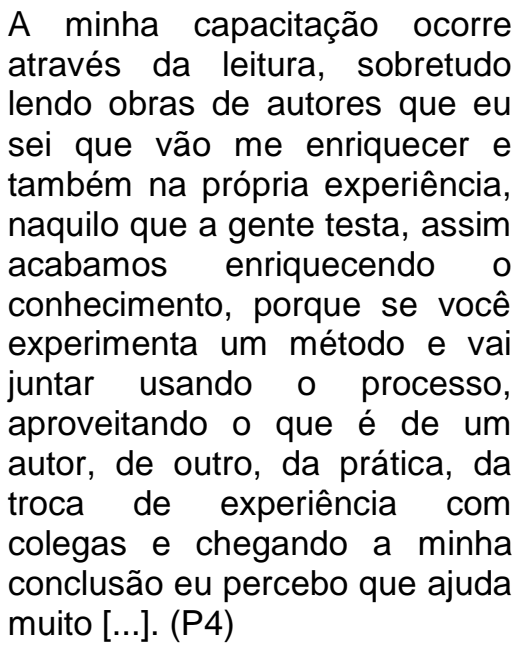

Neste sentido nos valemos da concepção de Imbernón (2009) considerando que o processo de formação permanente do professor deve acontecer através da reflexão prático teórica sobre a prática possibilitando o professor gerar 
conhecimento pedagógico por meio da sua prática educativa, do conhecimento possibilitado pela troca de experiências entre os seus pares, da união da formação à um projeto de trabalho, da formação como estímulo crítico ante práticas profissionais como o individualismo, a exclusão, a intolerância, assim como do trabalho conjunto possibilitando o desenvolvimento da instituição educativa através da transformação da prática.

\section{A INSERÇÃo E A ATUAÇÃO DOCENTE NO ENSINO SUPERIOR}

Sobre a inserção como docente no ensino superior verificamos que a maioria dos professores ingressou através de um convite.

O tempo de atuação destes professores na docência universitária varia entre 2 a 10 anos.

Entretanto, os mesmos possuem experiência enquanto docente em outros níveis de ensino: um já atuou na educação infantil e no ensino fundamental - $1^{\circ}$ a $5^{\circ}$ ano, dois no ensino fundamental - 6ำ a 9ano, dois no ensino médio, um na Educação de jovens e adultos, um na educação profissional (cursos técnicos) e em cursos de pós-graduação lato sensu.

Porém o fato dos professores terem experiência em outros níveis de ensino não pode ser entendido enquanto um fator que contribui para a sua ação docente no ensino superior.

Mazetto (2003, p. 25) afirma que a docência no ensino superior exige competências próprias que, se desenvolvidas trariam a esta atividade:

[...] uma conotação de profissionalismo e superaria a situação até então muito encontradiça de ensinar por "boa vontade", buscando apenas certa consideração pelo título de "professor de universidade", ou apenas para "complementação salarial", ou ainda somente para se "fazer alguma coisa no tempo que restasse do exercício da outra profissão".
O regime de trabalho dos professores nesta instituição de ensino superior é, na maioria, ou seja, 64\% horista e $33 \%$ parciais. Consideramos que o regime de trabalho horista não privilegia a troca de experiência entre os mesmos, não possibilitando, neste sentido, uma formação continuada a partir da aprendizagem com os colegas de trabalho. Neste sentido Cunha (1998, p. 35) evidencia que:

[...] o valor que os professores dão à prática docente enquanto a sua grande inspiração para a mudança e ao saber que se constroem a partir daí. Nela localizam a possibilidade de aprender com os colegas de trabalho, com alunos e de refletir sobre a própria docência, reformularem sua forma de pensar e agir.

Verificando a atuação docente no ensino superior constatamos que a mesma prioriza o ensino, com pouco envolvimento com a extensão e nenhum com a pesquisa, não possibilitando, portanto articulação entre ensino - pesquisa e extensão.

Corroboramos com Carvalho (1996, p. 14) no sentido de que é necessária uma articulação entre o ensino-pesquisa e extensão na docência universitária.

[... um ensino alheio à
pesquisa, tornar-se repetitivo,
não evolutivo, pouco
demonstrável, rapidamente
arcaizado e alheio ao processo
de evolução sócio-político-
técnica. A pesquisa, distante do
ensino e da extensão, tornasse
algo individualizado ou
exclusivamente voltado ao lucro,
ou à evolução tecnológica. Não
há necessidade de se explicitar
que a extensão perde seus
objetivos, numa universidade
sem o ensino e a pesquisa.

Acreditamos que é necessário que o professor reveja a maneira de conduzir a sua prática pedagógica, refletindo sobre ela, mobilizando seus saberes na ação de ensinar. 
OS SABERES DO PROFESSOR ATUANTE NO CURSO DE PEDAGOGIA.

Sobre o conceito de saber docente há um consenso teórico em que este é constituído por outros saberes derivados do conhecimento geral e pedagógico e da experiência profissional. Estes saberes são categorizados de diferentes formas por vários autores. O quadro abaixo mostra esta categorização:

Quadro 1. Categorização dos saberes docentes

\begin{tabular}{|c|c|c|c|c|}
\hline $\begin{array}{c}\text { Tardif , Lessard e } \\
\text { Lahaye (1991) }\end{array}$ & $\begin{array}{l}\text { Shulman } \\
\text { (2005) }\end{array}$ & $\begin{array}{l}\text { Pimenta } \\
\text { (1999) }\end{array}$ & $\begin{array}{c}\text { Gauthier et al } \\
\text { (1998) }\end{array}$ & Saviani (1996) \\
\hline $\begin{array}{ll}\begin{array}{l}\text { 1. saberes } \\
\text { formação }\end{array} & \text { da } \\
\text { profissional; } & \\
\text { 2. saberes das } \\
\text { disciplinas; } \\
\text { 3. saberes } \\
\text { curriculares; } \\
\begin{array}{l}\text { 4. saberes } \\
\text { experiência; da }\end{array}\end{array}$ & $\begin{array}{l}\text { 1.conheciment } \\
\text { o do conteúdo } \\
\text { (content } \\
\text { knowledge); } \\
\text { 2.conheciment } \\
\text { o do conteúdo } \\
\text { no ensino } \\
\text { (content } \\
\text { knowledge in } \\
\text { teaching) } \\
\text { 3.conheciment } \\
\text { o Pedagógico } \\
\text { (pedagogical } \\
\text { knowledge) }\end{array}$ & $\begin{array}{l}\text { 1. saberes da } \\
\text { experiência; } \\
\text { 2. saberes do } \\
\text { conhecimento; } \\
\text { 3. saberes } \\
\text { pedagógicos; }\end{array}$ & 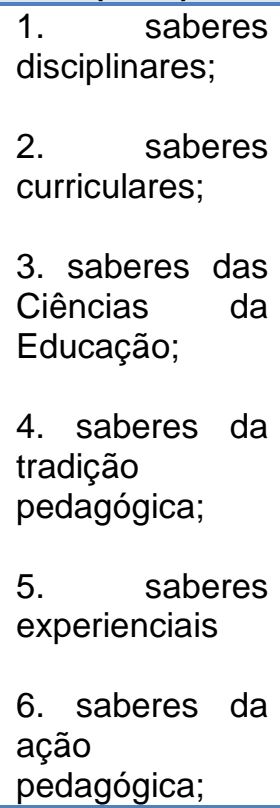 & $\begin{array}{l}\text { 1. saber atitudinal; } \\
\text { 2. saber crítico- } \\
\text { contextual; } \\
\text { 3. saber específico } \\
\text { 4. saber } \\
\text { pedagógico; } \\
\text { 5. saber didático- } \\
\text { curricular; }\end{array}$ \\
\hline
\end{tabular}

Tardif (2002), Shulman (2005), Pimenta (2002), Gauthier et al. (1998) e Saviani (1996), são unânimes em dizer que o saber docente não é algo que permeia o espaço sem relação com e no mundo, mas sim um saber ancorado por aspectos que se encontram relacionados com sua história de vida pessoal, acadêmica e profissional. Portanto é inviável considerar no processo educativo o saber fragmentado, pois os saberes são provenientes de várias situações em que 0 sujeito está inserido.

Analisaremos a seguir os saberes constitutivos da docência dos professores atuantes no curso de Pedagogia, a partir da categorização dos saberes em: saberes da formação, saberes do conhecimento pedagógico e saberes da experiência. Estas categorias emergiram a partir da articulação dos referenciais teóricos estudados.

\section{SABERES DA FORMAÇÃO}

Compreende a análise dos saberes transmitidos pelas instituições de formação de professores, envolvendo as teorias e informações que os estes receberam na sua formação. Refere-se aos conteúdos específicos da disciplina que o professor ministra.

As análises desta categoria teve como aporte teórico as concepções de Tardif (2002) relativas aos saberes da formação profissional, Gauthier et al. (1998) referente aos saberes das ciências da educação, Pimenta (2002) no que tange aos saberes do conhecimento, Saviani (1996) atinente ao saber específico e pedagógico 
e Shulman (2005) concernente ao conhecimento do conteúdo (content knowledge).

Sobre a aprendizagem da docência durante a licenciatura Tardif (2002) salienta que os saberes pedagógicos apresentam-se como doutrinas que fornecem um arcabouço ideológico à profissão, assim como algumas formas e técnicas de saber-fazer.

Podemos observar na fala dos professores, quando questionados sobre o que aprendeu na licenciatura, indícios deste arcabouço ideológico como também a aprendizagem de técnicas:

Eu tive uma formação teórica muito grande, das teorias de aprendizagens, metodologia, didática, então eu tive um alicerce bom para a minha prática profissional!. (P3)

[...] a gente aprendia a trabalhar através da metodologia, do material didático, aprendia a importância de cada um destes. Aprendia as metodologias adequadas e as que não eram adequadas. Havia a indicação de bons materiais didáticos e como utilizá-los. (P2)

Há um consenso entre os entrevistados que os saberes da formação profissional do professor são indispensáveis à prática docente, pois para ser professor um dos pilares é ter conhecimento sobre o que vai ser ensinado. Algumas falas expressam nitidamente esse pensamento:

$O$ curso de pedagogia te possibilita um conhecimento teórico que é fundamental para auxiliar na prática pedagógica. (P6)

$\mathrm{Na}$ licenciatura foi excelente $\mathrm{O}$ curso, os conteúdos foram ao encontro daquilo que eu buscava e me enriqueceu muito. Estes conteúdos são essenciais para minha prática enquanto docente. (P4)

Analisando como os saberes da formação auxiliam na prática pedagógica percebemos nos discursos dos professores um absolutismo destes saberes em detrimento de outros.

Os saberes que eu tenho foram advindos de professores, uma bagagem bem grande. [...] $O$ conhecimento obtido pelas matérias pedagógicas eu tive nos quatro anos de faculdade, são 0 que norteiam minha prática até hoje. (P5)

Os saberes da licenciatura me auxiliam principalmente com 0 conhecimento pedagógico [...]. (P6)

Referente a este absolutismo dos saberes da formação enquanto norteadores da prática docente Shulman (2005) alerta que o conhecimento do conteúdo é necessário, mas não suficiente para que a disciplina seja ensinada e aprendida com sucesso.

\section{SABERES DO CONHECIMENTO PEDAGÓGICO}

São os saberes que o professor deve adquirir a através do conhecimento das teorias e técnicas pedagógicas, das metodologias e da dinâmica do trabalho pedagógico (planejamento, a gestão, organização e avaliação) que vai determinar o trabalho do professor. Estes saberes são oriundos das disciplinas da formação inicial e continuada do professor.

Como aporte teórico à análises realizadas utilizamos as concepções de Tardif (2002) e Gauthier et al. (1998) relativas aos saberes disciplinares e curriculares, Pimenta (1999), no que tange ao saber pedagógico, Saviani (1996) atinente ao saber atitudinal, crítico-contextual e didático curricular assim como Shulman (2005) concernente ao conhecimento pedagógico (pedagogical knowledge).

Referente às metodologias utilizadas pelos professores percebemos que existe uma predominância na utilização da aula expositiva:

A que eu mais utilizo é a aula expositiva dialógica. (P5)

Eu uso a apostila que elaboro, primeiro eu dou as linhas gerais 
do conteúdo da apostila através da aula expositiva, depois eu devido a apostila em grupos vamos supor, em seis grupos e cada grupo vai ler e fazer perguntas [...].(P3)

Neste sentido entendemos que estes docentes compreendem 0 ensino como transmissão de conhecimento. A fala do professor P6 confirma esta afirmação:

[...] Percebo que o aluno aprendeu quando este faz a avaliações e consegue colocar com as palavras dele o que eu falei em sala de aula. (p6)

Corroboramos com a concepção de Freire (2003, p. 47) que "ensinar não é transferir conhecimento, mas criar as possibilidades para sua própria produção ou a sua construção". Portanto ensinar é um processo na busca da autonomia, é transformar o saber escolar em saber que pode ser utilizado em benefício da sociedade.

Ressaltamos que a mobilização dos saberes é pré-requisito importante para a contextualização do movimento de criação, realização e avaliação dos saberes produzidos nas práticas pedagógicas docentes.

Referente à dinâmica do trabalho pedagógico, percebemos que as formas de planejamento utilizadas pelos professores são o Projeto Pedagógico do Curso, o Plano de ensino semestral e, em alguns casos o plano de aula. Observamos que o planejamento não ocorre de forma conjunta, portanto, a dialogicidade entre os professores no que tange ao planejamento não acontece. Neste sentido Furlan e Hargreaves (2000, p. 20) salientam que:

Ensinar, há muito tempo, é conhecido como "uma profissão solitária" [...] $\mathrm{O}$ isolamento profissional limita o acesso a novas ideias e soluções melhores, acumula estresse internamente como uma chaga, fracassa em reconhecer e em elogiar o sucesso e permite a existência e a permanência da incompetência [...].

Enquanto fatores que favorecem 0 isolamento os autores destacam: a arquitetura escolar que isola espaços e segregam pessoas, os horários rígidos e uma organização inflexível da rotina escolar que impede as interações sociais e a sobrecarga de trabalho que dá sustentação ao individualismo.

Certa incoerência entre as teorias professadas e as praticadas pode ser verificada quando os professores explicitaram os objetivos da sua prática pedagógica. Apesar de contrariar algumas práticas analisadas acima, os professores utilizaram, pelo menos nas suas falas, conceitos de transformação social e autonomia como pode ser observado abaixo:

[...] o objetivo maior mesmo é o
aprendizado, é estar preparando
este profissional para que ele
consiga na sua prática atuar da
melhor forma possível, ter
conhecimento. (P6)
[... o meu primeiro
compromisso é com a
transformação social, então eu
trabalho para que haja uma
melhoria na sociedade. (P3)

Percebemos, portanto, uma dicotomia entre o discurso e a ação destes professores. Neste sentido Duarte (2003, p. 606) salienta que "a superação desse problema não estaria na busca de coerência com a teoria professada, mas sim no seu abandono e no reconhecimento de que a verdadeira teoria é aquela que está implícita na prática”.

\section{SABERES DA EXPERIÊNCIA}

É o saber adquirido no espaço da docência, desde quando aluno até enquanto professor quando é produzido constantemente na prática docente nas relações entre professores, entre estes e os alunos, a escola e sua organização e entre os professores e os seus 
próprios saberes, num processo de reflexão e troca de experiências com os colegas.

Como aporte teórico às análises deste tópico utilizamos as concepções de Tardif (2002) relativas aos saberes experienciais, Gauthier et al. (1998) referente aos saberes experienciais e da ação pedagógica, Pimenta (1999), no que tange ao saber da experiência e Shulman (2005) concernente ao conhecimento do conteúdo no ensino (content knowledge in teaching).

Tardif (2002, p. 54) salienta que os saberes experienciais:

[...] surgem como núcleo vital do saber docente, núcleo a partir do qual os professores tentam transformar suas relações de exterioridade com os saberes em relações de interioridade com sua própria prática. Neste sentido, os saberes experienciais não são saberes como os demais; são, ao contrário, formados de todos os demais, mas retraduzidos, "polidos" e submetidos às certezas construídas na prática e na experiência.

Quando os professores foram questionados que experiências, contextos foram mais significativos e ofereceram subsídios para a docência no ensino superior, estes foram unânimes em citar a aprendizagem através da relação professor-aluno. Não foi identificada nenhuma fala referente à situações que propiciam saber experiencial a partir das relações com seus pares.

Para Schön (1995) é necessário que a prática docente seja permeada por um processo de reflexividade envolvendo a reflexão na ação (durante a prática), reflexão sobre a ação (após a prática) e reflexão sobre a reflexão na ação, quando a ação é revista e analisada fora do contexto. Acreditamos que a prática reflexiva é fundamental na construção dos saberes da experiência.
Por fim entendemos que o ensinar envolve um arcabouço de saberes que se apresentam na própria ação docente. Ou seja, o saber docente é formado tanto nas práticas como nas teorias da educação. Isso remete à compreensão de que o trabalho docente se concretiza através da práxis, na relação teoria e prática referendada na reflexividade (açãoreflexão-ação).

\section{CONCLUSÃO}

O presente trabalho surgiu da inquietação em compreender a trajetória e os saberes dos professores atuantes no curso de Pedagogia em uma instituição privada, analisando a sua formação, suas concepções, influências sofridas e experiências vividas, a fim de traçar um perfil destes docentes.

Ao longo do percurso investigativo que envolveu esta dissertação muitas reflexões permearam o processo o qual teve como fio condutor uma instigante procura de respostas sobre questões que pairam na realidade da docência no ensino superior, a partir do diálogo estabelecido entre os referenciais teóricos e os dados revelados na pesquisa.

Imbuídos desse interesse em querer compreender o perfil do professor atuante no curso de Pedagogia em uma instituição privada verificamos que estes são, em sua maioria, do sexo feminino, casados, com idade entre 25 a 64 anos, todos cursaram o ensino médio em escolas públicas e o ensino superior (graduação e pósgraduação) em instituições privadas.

Referente à trajetória formativa do professor do curso de Pedagogia os resultados evidenciam que a escolha profissional e a formação dos professores sujeitos desta pesquisa contemplam a atuação docente na educação básica. Não foram identificadas formas de capacitação para o ensino superior, nem por parte dos docentes nem por parte da instituição, 
uma vez que o Núcleo de Apoio Pedagógico, que teria esta função realiza apenas orientação pedagógica a estes professores, não possibilitando momentos de reflexão sobre a prática docente. Evidenciamos, portanto, uma lacuna existente na preparação para a docência no ensino superior.

Quanto à escolha da profissão docente, os dados revelaram que esta ocorreu, na maioria por influência dos professores que ministraram aulas na educação básica, porém não foi citada por nenhum dos sujeitos da pesquisa qualquer influência de professor do ensino superior na sua prática pedagógica.

Sobre o início da carreira docente no ensino superior constatamos que este é permeado por momentos de descoberta concomitante com o choque com a realidade. Isso foi evidenciado inclusive entre os professores que já possuíam vários anos de experiência enquanto docentes na educação básica.

Neste sentido percebemos que o choque com a realidade pode ocorrer não só com professores iniciantes na docência, mas também com professores ingressantes em outro nível de ensino ainda não trabalhado.

A antecipada entrada no mercado de trabalho em detrimento ao tempo de formação também nos chamou a atenção, pois constatamos que esta situação criou nos professores uma falsa ideia de suficiência da vocação para o exercício do magistério.

A partir dos estudos sobre as fases do desenvolvimento profissional dos docentes, detectamos que com o passar do tempo de carreira, os saberes profissionais dos docentes vão sendo adquiridos por meio de experiências centradas no espaço escolar. Porém, não identificamos momentos de socialização destas experiências. Como fatores impeditivos destes momentos destacamos o regime de trabalho horista adotado para a maioria dos professores, a forma de planejamento isolado e a atuação do NAP, na qual pode ser evidenciada a precariedade de ações de apoio pedagógico que não possibilitam estes momentos de socialização de experiência.

A inserção destes docentes no ensino superior ocorreu "por acaso". Atribuímos este "acaso" à ausência de exigência legal e institucional no que se refere a uma formação específica para a docência universitária. Averiguamos que nos critérios de seleção docente adotado pela instituição de ensino superior campo desta pesquisa, há uma predominância na verificação do domínio do conhecimento específico da disciplina a ser ministrada em detrimento à preparação pedagógica. Esta situação reforça a concepção de que para ministrar aulas no ensino superior basta conhecer o conteúdo específico de uma disciplina.

Para alguns sujeitos deste estudo a inserção enquanto docente do ensino superior veio afirmar sua competência profissional em outra área que não a docência.

Observamos que na inserção no magistério superior não houve, nem por parte da instituição nem pelos professores, preocupação no que se refere à profissão docente e suas especificidades, tais como conhecimento pedagógico, domínio de métodos e técnicos de ensino, dentre outros. Esta aprendizagem pedagógica ocorreu com o tempo, ou melhor, com a prática.

Acreditamos que a atuação docente no ensino superior demanda mais do que apenas domínio de conhecimentos a serem transmitidos por um professor, exige competências próprias da docência que incluem concepções de ensino, de aprendizagem, de avaliação, de formação, bem como redimensionam constantemente 0 aprofundamento em todas elas, envolvendo 0 docente em um processo de formação 
permanente que perpassa por toda sua formação profissional continuando na sua prática docente.

Atinente à atuação docente no ensino superior constatamos que a mesma prioriza 0 ensino, com pouco envolvimento com a extensão e nenhum com a pesquisa, não possibilitando, portanto articulação necessária entre ensino, pesquisa e extensão.

A ausência de envolvimento dos docentes com a pesquisa está atrelada à falta de preparação (titulação), que ocasiona uma restrição da atividade docente ao ensino transformando o professor, muitas vezes, em um repetidor de informações.

Ao analisar os saberes destes professores notamos um absolutismo dos saberes da formação, oriundo dos conteúdos específicos da disciplina que o professor ministra.

É evidente a dicotomia entre o discurso (teorias professadas) e a ação (teorias praticadas) destes professores.

Detectamos a predominância pela aula expositiva, sendo o ensino entendido como transmissão de conhecimento.

Sobre o absolutismo dos saberes da formação enquanto norteadores da prática docente Shulman (2005) alerta que o conhecimento do conteúdo é necessário, mas não suficiente para que a disciplina seja ensinada e aprendida com sucesso.

Analisando os saberes do conhecimento pedagógico identificamos que existe uma clara fragmentação da relação teoria e prática, no sentido de que o saber está somente do lado da teoria.

Verificamos que a maioria dos professores concebe e trabalha a teoria e prática de forma racionalista: primeiro a teoria, verdade indiscutível, depois a aplicação prática, como confirmação da teoria ou como adequação da teoria à realidade, através de exemplos.
Entendemos que a teoria isolada não tem condições de transformar a realidade, ela ajuda a prática, apontando objetivos, buscando explicar resultados, possibilitando a reformulação de produtos. Neste sentido a teoria renova-se e confirma-se na conexão com a prática.

Observamos que a dialogicidade entre os professores no que tange ao planejamento não acontece, pois em nenhum momento do planejamento envolve o trabalho coletivo entre docentes.

Analisando a fala dos professores no que tange ao objetivo da disciplina percebemos que há uma preocupação por parte dos mesmos com a qualidade e não meramente com a quantidade do conteúdo trabalhado.

Identificamos também professores que não conseguiram expressar o objetivo da disciplina que ministram, consequentemente não deixam clara (ou não têm clareza) da sua ação pretendida.

Neste sentido constatamos uma limitação do saber profissional no que tange à consciência da sua ação pedagógica.

Os elementos constitutivos dos saberes experienciais citados pelos professores compreendem a vivência dos sujeitos da pesquisa enquanto alunos (o resultado das relações e as observações da prática pedagógica dos seus ex-professores) e a aprendizagem enquanto docente através da relação professoraluno.

Não foram identificadas no discurso dos professores situações que propiciam saber experiencial a partir das relações com seus pares.

Ressaltamos que esta relação dialógica não deve existir apenas entre professor-aluno, mas também entre os professores, auxiliando a construção dos saberes experienciais e possibilitando a reflexividade da prática docente, uma vez que existe um saber que se dá no fazer. 
A partir dessa compreensão vislumbra-se a necessidade de mudanças. È necessário que a instituição campo desta pesquisa invista na formação pedagógica docente visando à melhoria da qualidade pedagógica de todos os seus cursos e de seus professores em exercício. Para tanto deve reorganizar o Núcleo de Apoio Pedagógico a fim de que o mesmo além das capacitações ofereça também momentos de socialização e reflexão da prática pedagógica, possibilitando a efetiva colaboração profissional entre os professores, transformando a IES em uma comunidade de aprendizagem na qual os professores se apoiam e se estimulam mutuamente.

É preciso que a prática profissional seja compreendida, pelos docentes, enquanto momento de construção de conhecimentos, através da reflexão, análise e problematização desta, efetivando, assim o que Schön (2000) denomina "epistemologia da prática".

Porém, para que sejam possíveis estes momentos a instituição precisa também ampliar a carga horária de trabalho dos professores permitindo assim um tempo, fora das horas destinadas à docência, para que este participe das atividades propostas pelo NAP, além de possibilitar a troca de experiências entre docentes.

Faz-se necessário ainda que as ações desenvolvidas no NAP possibilitem ao docente à ampliação de sua consciência profissional uma vez que a atuação docente exige também um profissionalismo semelhante aquele exigido para o exercício de qualquer profissão.

Outra situação que merece destaque nas ações institucionais refere-se ao início da docência no ensino superior. É preciso que a instituição de ensino assuma o choque com a realidade através do oferecimento de programas de formação para professores principiantes que vise promover a adaptação e integração do novo docente à cultura escolar existente.

É indispensável investir também no fomento e na conscientização da importância da qualificação docente por meio dos programas stricto sensu.

A atuação docente no ensino superior não pode privilegiar o ensino. É necessária uma articulação entre ensino-pesquisa e extensão. Corroboramos com Giroux (1997) na concepção de que o docente, enquanto intelectual crítico que deve ser, precisa exercitar o pensamento dialético, ligando-se tanto à crítica como à reconstrução teórica, e não somente à sua reprodução.

Por fim entendemos que para a docência no ensino superior, é imprescindível uma preparação específica, a fim de que além das competências pedagógicas o docente seja crítico, reflexivo, pesquisador, criativo, inovador, questionador, articulador e se reconheça enquanto profissional.

\section{REFERÊNCIAS}

BRASIL. MEC/INEP. Sinopse Estatística da Educação Superior 2008 - Graduação. Brasília: MEC/INEP. 2009

Congresso Nacional. Lei 9.394 de 20 de dezembro de 1996. Estabelece as diretrizes e bases da educação nacional. Diário Oficial da União, Brasília, DF, 23 dez. 1996.

Evolução da Educação Superior -

Graduação. Brasília: MEC/INEP, 2000. Disponível em: <http://www.inep.gov.br/superior/censosuperior/ev olucao/evolucao.htm>. Acesso em: 16 de março 2010.

Sinopse Estatística da Educação Básica 2008. Brasília: MEC/INEP, 2009. Disponível em: $<$ http://www.inep.gov.br/basica/censo/Escolar/Sin opse/sinopse.asp $>$. Acesso em: 16 de março 2010.

CARVALHO, E. B. Indissociabilidade entre ensino, pesquisa e extensão nas universidades catarinenses. Salamanca: KADMOS, 1996. 
CUNHA, E. R. Os saberes docentes ou saberes dos professores. Revista Cocar, Belém-PA: UEPA, v. 1, n. 2, 2007, p. 31-39.

CUNHA, M. I. da. O professor universitário na transição de paradigmas. Araraquara: JM, 2005.

DUARTE, N. Conhecimento tácito e conhecimento escolar na formação do professor (por que Donald Schön não entendeu Luria). In: Educação \& Sociedade, v. 24, n. 83, p. 601-625, ago. 2003. Disponível em: <http://redalyc.uaemex.mx/src/inicio/ArtPdfRed.js p?iCve $=87313721015>$. Acesso em: 25 abril 2011.

FREIRE, P. Pedagogia da autonomia. Rio de Janeiro: Paz e Terra, 2003.

FURLAN, M.; HARGREAVES, A. A escola como organização aprendente: buscando uma educação de qualidade. Porto Alegre: Artes Médicas Sul, 2000.

GAUTHIER, C. et al. Por uma teoria da pedagogia: pesquisas contemporâneas sobre 0 saber docente. ljuí: UNIJUí, 1998.

GIL, A. C. Metodologia do Ensino Superior. 3. ed. São Paulo: Atlas, 1997.

GIROUX, H. Pedagogia racial: subsídios. São Paulo: Cortez: Autores Associados, 1997.

GRILLO, M. C.; MATTEI, P. Saberes docentes, identidade profissional e docência. In: ENRICONE, D.; GRILLO, M. C. (Orgs.). Educação Superior: vivências e visão de futuro. Porto Alegre: EDIPUCRS, 2005. p. 99-110.

IMBERNÓN, F. Formação docente e profissional: formar-se para a mudança e a incerteza. 7. ed.. São Paulo: Cortez, 2009.

MASETTO, M. T. Docência na universidade. Campinas, SP: Papirus, 1998.

Competência Pedagógica do Professor universitário. São Paulo: Summus, 2003.

PIMENTA, S. G. (org.) Saberes pedagógicos e atividade docente. 3. ed. São Paulo: Cortez, 2002.

SAVIANI, D. Os saberes implicados na formação do educador. In: BICUDO, M. A.; SILVA JUNIOR, C. A. (Orgs.). Formação do educador: dever do Estado, tarefa da Universidade. São Paulo: Unesp. 1996. p. 145-155.

SCHÖN, D. A. Formar professores como profissionais reflexivos. In: NÓVOA, A. (org.). Os professores e a sua formação. Lisboa: $D$. Quixote, 1995. p. 77-91.

SHULMAN, L. S. Conocimiento y enseñaza: fundamientos de las nueva reforma. Professorado. Revista de currículum y formación del profesorado. Granada Espanha, v. 9, n. 2, p.1-25, 2005.

TARDIF, M. Saberes Docentes e Formação Profissional. Petrópolis: Vozes, 2002.

VASCONCELOS, M. L. M. C. A formação do professor do ensino superior. 2.ed. São Paulo: Pioneira, 2000. 